\title{
Characterization of ductile fracture properties of quench-hardenable boron steel: Influence of microstructure and processing conditions
}

\author{
Stefan Golling ${ }^{\mathrm{a}, *}$, Rickard Östlund ${ }^{\mathrm{b}}$, Mats Oldenburg ${ }^{\mathrm{a}}$ \\ ${ }^{a}$ LuleåUniversity of Technology, SE 97187 Luleå, Sweden \\ ${ }^{b}$ Gestamp HardTech, Ektjärnsvägen 5, SE 97345 Luleå, Sweden
}

\begin{abstract}
Developments of the hot stamping technology have enabled the production of components with differential microstructure composition and mechanical properties. These can increase the performance of certain crash-relevant automotive structures by combining high intrusion protection and energy absorption. This paper presents a comprehensive experimental investigation on the flow and ductile fracture properties of boron-alloyed steel with a wide range of different microstructure compositions. Three types of dual phase microstructures at three different volume fractions, and one triple phase grade, were generated by thermal treatment. Flow curves extending beyond necking and the equivalent plastic strain to fracture for each grade was determined by tensile testing using fullfield measurements. The influence of phase composition and microstructural parameters were further investigated by means of a multi-scale modeling approach based on mean-field homogenization in combination with local fracture criteria. Inter-phase and intra-phase fracture mechanisms were considered by adopting two separate fracture criteria formulated in terms of the local average stress field. The micromechanical model captures with useful accuracy the strong influence of microstructure and processing conditions on the flow and fracture properties, implying promising prospects of mean-field homogenization for the constitutive modeling of hot stamped components.
\end{abstract}

Keywords: ductility, fracture, heat treatment, mechanical testing, mean-field homogenization

\section{Introduction}

Continuous efforts by automotive manufacturers to reduce vehicle weight is of paramount importance to meet emissions legislation and reduce fuel con-

\footnotetext{
* Corresponding author

Email address: stefan.golling@ltu.se (Stefan Golling)
}

Preprint submitted to Materials Science and Engineering: A

January 28, 2016 
sumption, whilst still maintaining or increasing passive safety in crash situations. The increase in crashworthiness to weight ratio is partially addressed by the application of new advanced materials and manufacturing processes. One such technology is the simultaneous forming and heat treatment of boron alloyed sheet metal components, termed press-hardening or hot-stamping. During the last decade, much effort has been put in developing the manufacturing process to enable the production of components with spatially varying microstructure and properties, termed tailored properties (TP) components. Using special tool technology, with differential in-die cooling rates by heated tool sections and/or reduced thermal conductivity of the tool material, is one approach to obtain the desired microstructure composition and variation thereof within the final component. Distributed mechanical properties can be advantageous in terms of crash performance for certain parts of the vehicle structure, combining high intrusion protection and energy absorption.

To support the current development, a systematic investigation of the relative influence of various microstructural constituents on the overall flow properties and ductility of quench-hardenable boron alloyed steel is needed. To this end, we have designed processing routes to produce tensile specimens with a comprehensive range of different microstructures. These include dual phase ferritic-martensitic, ferritic-bainitic and bainitic-martensitic compositions, and a triple phase grade consisting of ferrite, bainite and martensite. Additionally, the aim of the current work is to explore the possibilities of a multi-scale modeling approach to ductile fracture prediction. Specifically, if the significant variations in strength and ductility arising from microstructural effects can be captured with useful accuracy, at a computational expense which can be used in crashworthiness predictions of automotive components with tailored properties. Developments concerning the constitutive modeling of boron alloyed steel that takes into account the processing history have been proposed by several investigators. Åkerström modeled the austenite decomposition into daughter phases during continuous cooling and extended it with a mechanical module to simulate the complete press hardening process $[1,2]$. In press hardening the boron alloyed steel $22 \mathrm{MnB} 5$ is a common choice in industrial application as in research and hence thoroughly investigated. Modeling the process from austenitization to finished product relies on in depth knowledge of parameters influencing the microstructural composition and the mechanical properties of the finished product. Besides the cooling rate the importance of considering hot plastic deformation in isothermal and non-isothermal forming operations are pointed out $[3,4,5]$.

Constitutive models for the use in hot stamping applications have typically been formulated with microstructure dependent coefficients, see e.g. [6, 7, 8, 9]. An alternative route is to estimate effective material properties based on the properties of the constituent phases and arrangement at the microscale. Homogenization schemes are numerical or analytical methods, devised to estimate macroscopic effective constitutive properties based on the microstructural behaviour. Belonging to numerical methods, the computational homogenization is based on discretized microgeometries for which they aim at fully accounting for the interactions between phases. 
Mean-field homogenization (MFH) approaches are analytical (semi-analytical in case of non-linear constituents) where the microfields within each phase are approximated by their phase averages. Approximations concerning field fluctuations, geometry and interactions at the microscale render a less computationally demanding scheme. The microgeometry enters the formulation through statistical measures such as volume fractions and phase topology. They provide estimates of the composite material behaviour and the average stress and strain fields as well as deformation histories within each present phase. A survey of these types of homogenization methods can be found in [10, 11, 12]. Fracture models can be formulated in terms of these microscopic average fields in order to estimate the ductility of the steel with respect to microstructure and process history. Methods to estimate the effective ductility of heterogeneous metals by a combination of MFH and various damage and/or fracture models have been proposed in literature. Tekoglu and Pardoen [13] integrated a Gurson type damage combined with MFH, where the damage model was applied to the homogenized material in a multi-step approach. They considered an elasto-plastic matrix material reinforced with elastic particles with reference to cast aluminium alloys. A systematic study of the influence on flow behaviour of the microstructural parameters of dual phase steels consisting of ferrite and martensite with preliminary results on fracture were presented by [14].

Ductile fracture is a field with intensive research focus for different materials and loading conditions. The microstructure of a material has a strong influence on fracture properties, typical influence factors are voids, inclusions and micro cracks. The nucleation of voids, their growth and coalescence, is usually seen as the predecessor of ductile fracture. Recently, Bai and Wierzbicki [15] published a comparative study on twelve ductile fracture models and divided them into three groups, physics based, empirical and phenomenological models. Two general types of approaches to capture ductile fracture are described in literature [16]. The first approach utilizes damage accumulation within the continuum, these models couple constitutive and fracture model. The second approach assumes fracture as a sudden event in an undamaged continuum where failure is postulated if the stress and strain state reaches a critical limit. In literature the former type is referred to as coupled and the latter as uncoupled fracture modeling. In the field of physics based, coupled, constitutive and ductile fracture models the stress-state dependence caused by growth and coalescence of micro-defects using numerical simulations of unit cells and experimental observations over a wide range of triaxialities is studied and good correlation is found $[17,18]$. Li et al. [19] present a detailed review of coupled and uncoupled damage criteria which are implemented in a commercially available FE code and compared to experimental results of tensile and compression tests with different specimen geometries. Malcher et al. [20] extended the GTN model with a shear mechanism and compared it to CDM based Lemaitre damage model and the Bai-Wierzbicki [21] model (termed B-W model), it is concluded that for high stress triaxiality the B-W model is in closer agreement with experimental results compared to GTN and Lemaitre's model, while for low triaxialities all constitutive models have limitations. For completeness it should be mentioned that the 
B-W, like the Johnson-Cook[22] model and CrashFEM ([23]), is an empirical based model. Among the phenomenological models are the oldest fracture models proposed, the maximum shear stress (MSS) and the Mohr-Coulomb criteria, for both aforementioned models literature reports modified versions. Cockcroft and Latham [24] proposed a ductile fracture criteria which integrates the maximum principal tensile stress over incremental plastic strain i.e. the energy density is calculated. Among the phenomenological fracture criteria the magnitude of stress vector (MSV) criteria was proposed more recently [25]. The MSV criterion showed good results in comparison to a number of phenomenological and empirical fracture criteria. Phenomenological models captivate due to their simplicity in calibration, usually only few specimen geometries are needed to obtain a small number of parameters.

Concerning quench-hardenable boron steel, recent experimental investigations have focused on materials characterization and on the manufacturing of components with distributed mechanical properties, among other aspects. In traditional hot stamping or press hardening the material properties are obtained by quenching of the blank. In order to obtain spatially varying mechanical properties within a single component special tool design and/or tool materials are necessary. The thermal conditions necessary to obtain TP components are a major field of interest. The tool design utilizes in-die heating and cooling as well as two different tool steels with varied thermal conductivity. A u-shaped beamed is formed showing martensite formation in the cooled section and a ferritic microstructure in the heated tool section [26]. Experimental evaluation of parameters influencing the press hardening process are performed on lab-scale TP component using in-die heating and cooling technology. The influence of tool temperatures and temperature gradients on phase formation is a crucial factor in the production of TP components [27]. Bardelcik et al. [6] based their constitutive model on experimental data obtained from specimens quenched at five different cooling rates, by forced air convection, producing microstructures that ranged from bainitic to martensitic, with intermediate mixed microstructures. In order to produce larger amounts of ferrite, a dual furnace and tool-quenching system can be used [28]. However, a study on the flow behavior and ductile fracture properties of boron steel with direct reference to the mechanical properties of the constituents and arrangement at the microscale is, to the authors knowledge, missing. Such an investigation is relevant in establishing predictive tools for determining performance envelopes of press hardened components with distributed microstructure composition.

In this work we employ a dual furnace and cartridge-heated plane quenching tool processing system to produce tensile specimens with an extensive range of microstructure compositions. Fracture data and flow curves extending to large plastic strains are obtained from tensile tests using full-field deformation measurements. We propose a multiscale approach to ductile fracture modeling within the framework of mean field homogenization. Two non-interacting fracture criteria are formulated in terms of the local average stress field, referring to inter-phase and intra-phase fracture mechanisms. The predicted overall ductility is governed by the weakest constituent or interface present in the multiphase 
material.

\section{Experiments}

The material investigated is a low alloyed boron steel, which is widely used in industry for hot stamped components. In as delivered condition, $22 \mathrm{MnB} 5$ exhibit homogeneous distribution of pearlite in an equiaxed grain ferritic matrix, the material is coated with an AlSi layer which protects from oxidation during heat treatment and corrosion during service life.

This section is intended to give a general overview of samples used for the study of fracture in mixed microstructures, the tool used for the heat treatment and sample production procedure used to obtain different microstructure compositions. The aim of the experimental study on a larger variety of mixed microstructures is to increase the understanding of their overall properties.

\subsection{Specimens}

Five types of sample geometries were cut perpendicular to rolling direction of the sheet using abrasive water jet cutting. The method for the extraction of test specimens from the blank has an impact on the elongation before fracture [29]. To keep edge effects marginal all water jet cut surfaces in the vicinity of the critical cross section were polished. The sheet thickness for all samples is $1.25 \mathrm{~mm}$. Schematic specimen geometries are shown in Fig. 1. The geometry of the specimens was dictated by the dimensions of the tool used during heat treatment. All specimens have the basic dimensions $240 \mathrm{x} 40 \mathrm{~mm}$.

\subsection{Production process of heat treated specimens}

The production process was designed with the purpose to: (i) produce tensile test specimens with distinctly different microstructures and varying amount of phase volume fractions; and, (ii) ensure those microstructures are relevant to those commonly found in hot stamped components. With differential indie cooling rates, ferritic-bainitic and bainitic-martensitic microstructures may form depending on the specific cooling rate. Less likely are the formation of ferritic-martensitic compositions during the forming process, due to the significant temporal variations in cooling rate required. However, ferritic-martensitic mixtures may form in the vicinity of welds, especially if welding is performed in fully martensitic material. To encompass all aforementioned microstructure compositions, we have chosen an iso-thermal transformation based process.

The equipment used for specimen heat treatment consists of two furnaces, a plane quenching tool and a water container. Prior to heat treatment, all samples were equipped with three thermocouples and are electrically grounded to data logging equipment in order to avoid interference during sampling. The temperature of the specimen was continuously monitored throughout the experiment.

All samples were austenitized in the first furnace at $1223 \mathrm{~K}\left(950^{\circ} \mathrm{C}\right)$ for four minutes. Samples were positioned on a brick in the center of the furnace to achieve even temperature distribution throughout heating. A second 

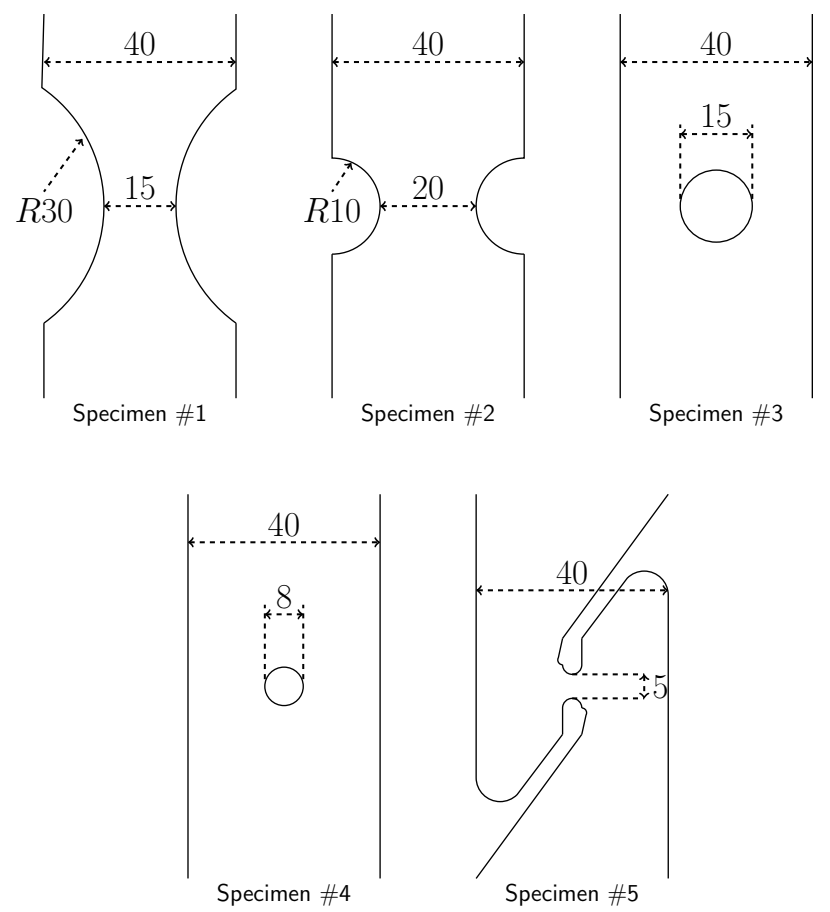

Figure 1: Overview of tensile specimens. Nominal sheet thickness is $1.25 \mathrm{~mm}$. All dimensions are in millimeters.

furnace was used to form ferrite; the temperature of this furnace was set to $923 \mathrm{~K}\left(650^{\circ} \mathrm{C}\right)$. Formation of bainite or martensite was possible in the plane quenching tool.

A schematic representation of the plane quenching tool is shown in Fig. 2. The tool uses two plane surfaces where an area of $200 \mathrm{x} 40 \mathrm{~mm}$ can be temperature controlled using cartridge heating. Specimens were cut $40 \mathrm{~mm}$ longer compared to the temperature-controlled tool area for handling purposes. The tool temperature was measured in six points, $2 \mathrm{~mm}$ beneath the surface, equally distributed along the tool length. To achieve even heat transfer between sample and tool a pressure of $20 M P a$ was applied onto the specimens. Symmetric contact conditions between tool and specimen are desired, therefore spring supported pins with a length of $2 \mathrm{~mm}$ are used in both tool halves.

For circumstances which required a heated tool, such as to produce bainiticmartensitic samples or composites consisting of three phases, the tool could not simultaneously be utilized as quenching device, thus water quenching was applied. The water temperature was kept at room temperature. A pre-study showed negligible discrepancy in mechanical properties between the tool and water quenched specimens. The production process was monitored by the real time data logging system, which enabled accurate manual transfers between production steps. 
An advantage of the production process used in this study is the control over transformation time and temperature independent of the specimen geometry. During transfer between furnace to furnace or furnace and tool the cooling rate may be different along the sample but the main part of the phase transformation is under temperature controlled conditions. Using a plane tool provides the advantage of equal pressure distribution on the specimen and, resulting in even heat transfer between tool and specimen. Cooling rates from the austenit region or ferrite formation temperature to bainite transformation are high due to efficient heat conduction between sample and tool. Rapid temperature change of the specimen allows short holding times leading to possible production of samples with smaller amounts of bainite. The production of three phase composites is possible by controlling temperature of transformation and holding times.

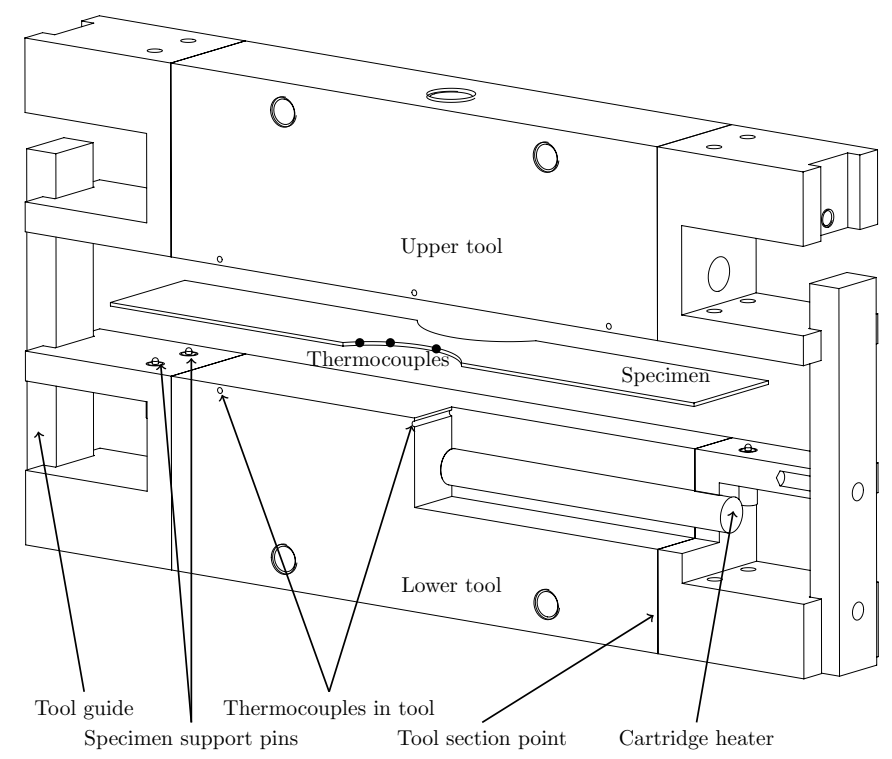

Figure 2: Schematic representation of the tool used to produce heat treated samples. On the test specimen three locations used for continuous temperature measurement are marked with dots. Insulation and limit stops are excluded for clarity.

\subsubsection{Mixed microstructures}

Ferritic-bainitic microstructures were produced by air cooling during transfer and holding at $923 \mathrm{~K}\left(650^{\circ} \mathrm{C}\right)$ in the second furnace to form ferrite, the remaining austenite is subsequently transformed into bainite in the heated tool. Samples of this type are henceforth abbreviated FB. In total three different combinations of ferritic-bainitic samples were produced. Similarly to the FB specimens, ferritic-martensitic specimens were produced by ferrite transformation at $923 \mathrm{~K}\left(650^{\circ} \mathrm{C}\right)$, but with subsequent tool quenching to room temperature. 
Forced air convection was applied to prevent heating of the tool during consecutive process steps. In total three different phase volume fractions are produced and subsequently labeled FM. Samples consisting of bainite and martensite are produced with the tool heated to $703 \mathrm{~K}\left(430^{\circ} \mathrm{C}\right)$ and subsequent quenching in water. The bainite transformation in $22 \mathrm{MnB} 5$ is a comparably fast process and therefore short holding times in the tool are used. Four samples with bainitic-martensitic microstructure are produced and are abbreviated as BM. A microstructure containing three distinct phases is produced by a combination of the two previous mentioned routines, ferrite formation at $923 \mathrm{~K}\left(650^{\circ} \mathrm{C}\right)$ and bainite formation at $703 \mathrm{~K}\left(430^{\circ} \mathrm{C}\right)$ with subsequent quenching in water to transform the remaining austenite into martensite, the sample is abbreviated FBM. A schematic representation of the heat treatment process is shown in Fig. 3 , the holding times $t_{f}$ and $t_{b}$ are adjusted depending on the desired volume fraction of phases. In Tab. 1 the holding times for all produced samples are given.

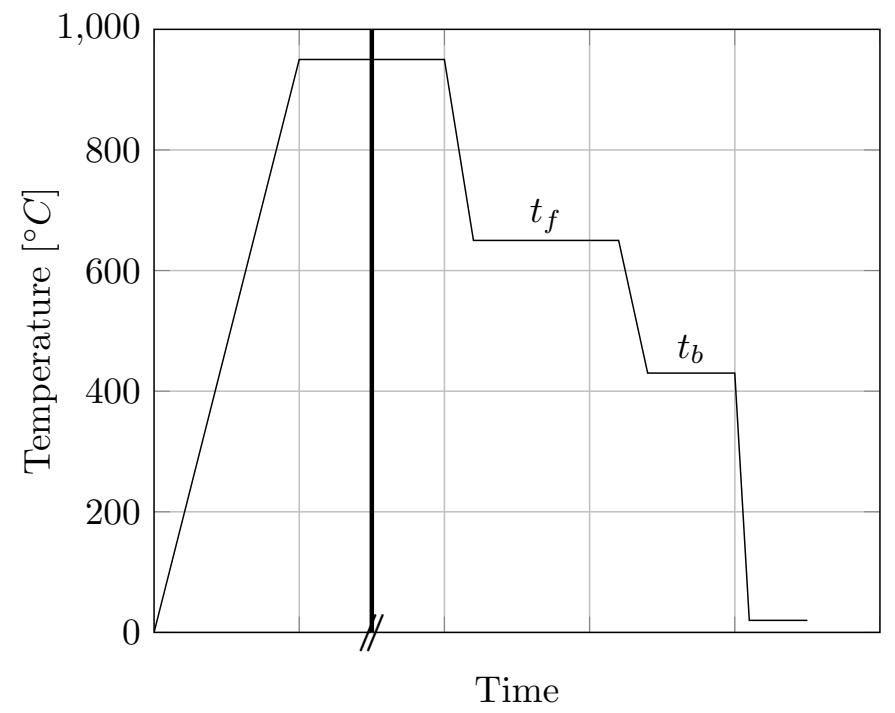

Figure 3: Schematic heat treatment cycle.

\subsubsection{Single phase microstructures}

For the purpose of calibrating the local plasticity model and fracture criteria, see Section 2.4, three single phase microstructures were produced, each consisting of predominantly ferrite, bainite and martensite, respectively. The term 'single phase' is used throughout this study and denotes microstructures consisting of more than $95 \%$ of the same type of phase. Specimens with ferritic and bainitic microstructures are available from an earlier study [30], where they were cut after heat treatment from larger blanks. Martensitic specimens were obtained by quenching the pre-cut specimen in the tool to room temperature. 
Since these specimens were produced for calibration purposes, all specimen geometries depicted in Fig. 1 were used. Single phase samples are henceforth abbreviated by their first letter and ultimate tensile strength, e.g. F730, B1015 and M1660.

\subsection{Microstructure characterization}

In this work the main characterization techniques were SEM/ EBSD and SEM imaging with subsequent image analysis. The measurements are made at one quarter of the blank thickness in order to avoid surface specific phenomena and center segregations. Prior to analysis the samples are wet ground, polished and etched.

For single phase data three microstructures were produced and results are presented in Tab 1 and section 2.2.2. The ferritic microstructure is described as 'irregular ferritic', this means that the morphology cannot be described as polygonal, but not either as acicular since no lath structure can be observed. Bainite was characterized as lower bainite, e.g. lath formed ferrite with fine carbides within the laths. Martensite was mainly found in a self tempered condition; this is typical for martensite that is formed at high temperature.

All mixed microstructures are characterized using SEM imaging except of the ferritic-martensitic samples which were made using EBSD data. For ferritemartensite samples the band slope information was used to separate the ferrite from the martensite. Ferrite found in the samples showed polygonal features but with irregular tendencies. All samples show small amounts of retained austenite, e.g. austenite that did not transform during cooling, distributed as small islands in the main phases. In Fig. 4 typical micrographs of mixed microstructures characterized in the framework of this study are depicted. The result of the microstructure characterization and a summary of all transformation times used in the production of samples is presented in Tab. 1.

\subsection{Plasticity and fracture}

Tensile tests were performed using a servo-hydraulic machine with a crosshead displacement rate of $0.1 \mathrm{~mm} / \mathrm{s}$. The digital image correlation (DIC) and acquisition system Aramis (GOM GmbH, Braunschweig, Germany) was used to record the displacement field of the specimen surface during loading. DIC is a common technique for the determination of fracture parameters of dual-phase steel. This technique is applicable to specimens which stay in-plane during loading as well as to out-of-plane tests like the Nakajima test [31]. Applying the DIC technique on microstructural level provides the possibility of visualizing the strain distribution in grains and grain boundaries up to the point of void formation [32]. DIC requires a random pattern on the specimen surface, the in-plane displacement of any small unique region can be determined by a crosscorrelation procedure of the digital images taken before and after deformation. To avoid decorrelation due to surface cracking of the AlSi coating, the speci-

men surface was sandblasted to remove the coating prior to tensile testing. The 


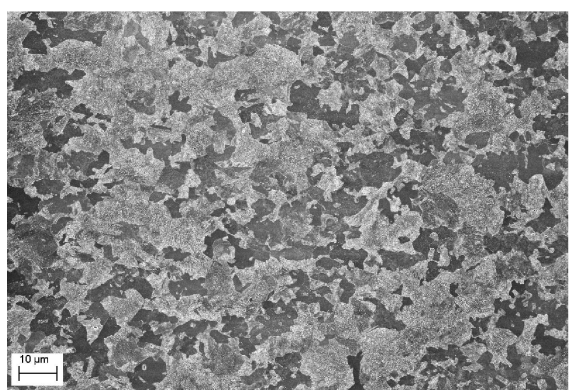

(a) Ferritic-martensitic microstructure of sample FM-1. Brighter areas are martensite, darker areas correspond to ferrite, area size $150 x 130 \mu m$ at a magnification of $2000 x$.

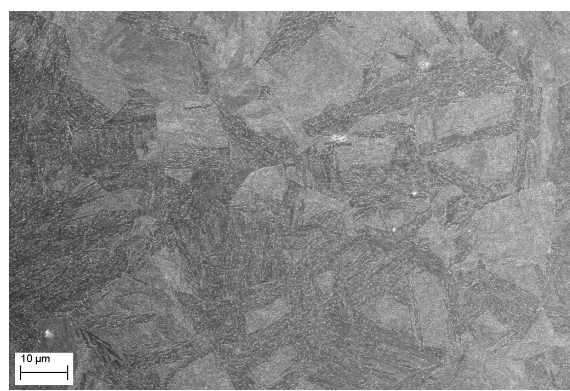

(c) Bainitic-martensitic microstructure of sample BM-3. Brighter areas are martensite, darker areas with dot pattern correspond to bainite, similar to sample FB-1 the white dots correspond to cementite.

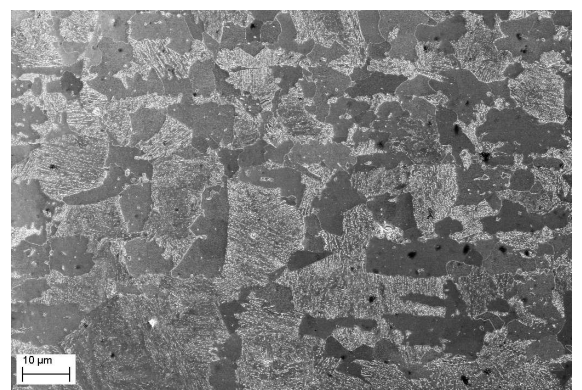

(b) Ferritic-bainitic microstructure of sample FB-1. Ferrite is gray colored and brighter areas are bainite. The white dots in the bainite grains is cementite.

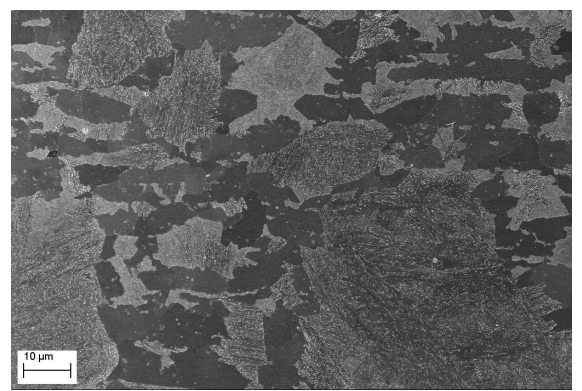

(d) Three phase microstructure consisting of ferrit, bainite and martensite. The dark gray areas are ferrite, darker areas with dot pattern are bainitic and light gray areas are martensite.

Figure 4: Examples of microstructures from scanning electron microscope. The area size is $120 x 80 \mu m$ at a magnification of $2500 \mathrm{x}$ if not indicated differently. 
Table 1: Phase volume fraction of test samples and holding times for ferrite and bainite formation. Balance in the phase volume fraction is the amount of retained austenite.

\begin{tabular}{|c|c|c|c|c|c|}
\hline Sample & $\begin{array}{l}\text { Ferrite } \\
\text { [vol.\%] }\end{array}$ & $\begin{array}{l}\text { Bainite } \\
\text { [vol.\%] }\end{array}$ & $\begin{array}{c}\text { Martensite } \\
\text { [vol.\%] }\end{array}$ & $\begin{array}{c}\text { Ferrite } \\
\text { formation } \\
\text { time } t_{f}[s]\end{array}$ & $\begin{array}{c}\text { Bainite } \\
\text { formation } \\
\text { time } t_{b}[s]\end{array}$ \\
\hline F730 & $95.0 \pm 2$ & $3.0 \pm 2$ & $\mathrm{x}$ & air cooled & 0 \\
\hline B1015 & $\mathrm{x}$ & $97.0 \pm 1$ & $1.5 \pm 1$ & air cooled & 0 \\
\hline M1660 & $\mathrm{x}$ & $\mathrm{x}$ & $98.5 \pm 1$ & 0 & 0 \\
\hline FM-1 & $50.8 \pm 3$ & $0.8 \pm 0.2$ & $48.8 \pm 3$ & 45 & 0 \\
\hline FM-2 & $62.1 \pm 3$ & $1.3 \pm 0.2$ & $36.3 \pm 3$ & 60 & 0 \\
\hline FM-3 & $74.0 \pm 3$ & $0.9 \pm 0.2$ & $23.5 \pm 3$ & 100 & 0 \\
\hline FB-1 & $32.5 \pm 2$ & $66.1 \pm 2$ & $0.9 \pm 0.2$ & 30 & 100 \\
\hline FB-2 & $49.0 \pm 2$ & $48.0 \pm 2$ & $2.6 \pm 0.2$ & 45 & 100 \\
\hline FB-3 & $57.5 \pm 2$ & $37.7 \pm 2$ & $4.3 \pm 0.2$ & 60 & 100 \\
\hline BM-1 & $\mathrm{x}$ & $22.5 \pm 4$ & $77.4 \pm 4$ & 0 & 8 \\
\hline BM-2 & $\mathrm{x}$ & $37.5 \pm 4$ & $62.3 \pm 4$ & 0 & 13 \\
\hline BM-3 & $\mathrm{x}$ & $66.2 \pm 4$ & $33.5 \pm 4$ & 0 & 17 \\
\hline BM-4 & $\mathrm{x}$ & $89.9 \pm 4$ & $10.0 \pm 4$ & 0 & 25 \\
\hline FBM-1 & $41.7 \pm 2$ & $36.1 \pm 2$ & $21.1 \pm 2$ & 44 & 13 \\
\hline
\end{tabular}

sandblasted surface showed enough contrast and pattern which made it unnecessary to spray paint the specimens. A frame rate of three images per second was used.

The experimentally determined displacement fields and force recordings constitute the basis for determining the flow curve up to large strains, as well as the stress tensor components and equivalent plastic strain values at the location and instant of fracture initiation. Details of this procedure, which is shortly described in the following, can be found in $[33,34]$. Using a $J_{2}$ plasticity model with isotropic hardening and piecewise linear flow curve representation,

$$
\sigma_{Y}^{n}=\sigma_{Y}^{n-1}+H^{n}\left(\bar{\varepsilon}_{p}^{n}-\bar{\varepsilon}_{p}^{n-1}\right), \quad n=1,2,3 \ldots n_{f},
$$

the stress field can be computed from the measured deformation. In Eq. 1, $\sigma_{Y}$ is the yield strength and $H$ is the plastic modulus, superscript denotes the load step where $n_{f}$ is the final step. When the stress field is known, the force acting on any cross-section (in the current deformed geometry) can be determined, and $H$ is determined iteratively in each load step $n$ so that the difference between measured and calculated force is minimized. Provided that the virgin yield strength $\sigma_{Y}^{0}$ is known, the flow curve can be constructed stepwise through the set of measured deformation fields up to fracture. This procedure uses solely experimental field data, avoiding detailed finite element analysis of each test and inverse modelling. We define that the instant of fracture initiation occurs 
during the load step directly preceding the first detectable discontinuity in the measured displacement field, denoted $n_{f}$. This procedure was used to extract flow and fracture data from all material compositions. Optical measurement systems are commonly used to determine material properties or displacement fields in multi-phase microstructures.

\section{Modelling}

Micromechanical modelling was performed to gain further insight into the deformation and fracture behaviour of the different microstructure compositions produced. In addition to this end, systematic investigations of the predictive performance of homogenization schemes in combination with various local fracture criteria could contribute to the establishment of predictive tools for design and development of press-hardened components with tailored properties.

\subsection{Mean-field homogenization}

Within mean field techniques the microscale stress and strain fields within each constituent are expressed through their phase averages $\langle\bullet\rangle_{(r)}$,

$$
\langle\sigma\rangle_{(r)}=\frac{1}{\Omega_{r}} \int_{\Omega_{r}} \sigma d \Omega, \quad\langle\varepsilon\rangle_{(r)}=\frac{1}{\Omega_{r}} \int_{\Omega_{r}} \varepsilon d \Omega
$$

where $\Omega_{r}$ is the subdomain occupied by phase $r$ within the representative volume element (RVE) domain $\Omega$. The average fields over the entire RVE domain, which correspond to the applied macroscopic fields, follows as

$$
\langle\sigma\rangle=\sum_{r} v_{r}\langle\sigma\rangle_{(r)}, \quad\langle\varepsilon\rangle=\sum_{r} v_{r}\langle\varepsilon\rangle_{(r)}
$$

where $v_{r}=\Omega^{r} / \Omega$ is the volume fraction of phase $r$. The per-phase average stress and strain fields are related to the overall fields by the stress and strain concentration tensors through

$$
\langle\sigma\rangle_{(r)}=\mathbf{A}_{(r)}:\langle\sigma\rangle, \quad\langle\varepsilon\rangle_{(r)}=\mathbf{B}_{(r)}:\langle\varepsilon\rangle .
$$

Various mean field homogenization models differs in their expressions for the fourth-order concentration tensors $\mathbf{A}^{(r)}$ and $\mathbf{B}^{(r)}$, however most rely on the solution for the elastic fields of a single inclusion embedded in an infinite matrix by Eshleby [35]. To account for collective interactions between inhomogeneities at non-dilute concentrations, Mori and Tanaka [36] replaced the macroscopic fields in Eqs. 4 with the average matrix fields, rendering in the following expression for the average strain within inclusion $r$,

$$
\langle\varepsilon\rangle_{(r)}=\mathbf{B}_{(r)}:\langle\varepsilon\rangle_{(m)}
$$

where subscript $m$ denotes the matrix phase and $\mathbf{B}_{(r)}$ the concentration tensor for the single inclusion,

$$
\mathbf{B}_{(r)}=\left[\mathbf{I}+\mathcal{E}:\left(\left(\mathbf{D}_{(m)}^{e}\right)^{-1}: \mathbf{D}_{(r)}^{e}-\mathbf{I}\right)\right]^{-1} .
$$


Here $\mathbf{I}$ is the fourth order identity tensor, $\mathcal{E}$ is the Eshelby tensor, $\mathbf{D}_{(r)}^{e}$ and $\mathbf{D}_{(m)}^{e}$ Hooke's elasticity tensor for inclusion phase $r$ and the matrix phase, respectively. For isotropic elasticity, the Eshelby tensor depends only on the semi-axes of the elliptic inclusion and the Poisson's ratio of the matrix. We consider an idealization of the multi-phase steel microstructures where we have a combination of non-dilute concentrations of inclusion phases that are dispersed within a distinct matrix phase to a certain degree, and that they may also form continuous interwoven networks. Consequently, we employ an homogenization model based on interpolation between the regular Mori-Tanaka (MT) model, and the inverse Mori-Tanaka where the material properties of the inclusion and matrix are permuted. This interpolation model was proposed by Lielens [37] and further explored by Doghri and Ouaar [38], where it was derived from reference [39] and thus referred to as the double inclusion (DI) model. In the form of incremental elasto-plasticity, the average strain rate of inclusion phase $r$ is related to the average matrix strain rate by

$$
\begin{aligned}
& \langle\dot{\varepsilon}\rangle_{(r)}=\mathbf{B}_{(r)}:\langle\dot{\varepsilon}\rangle_{(m)}, \text { where } \\
& \mathbf{B}_{(r)}=\left[\left(1-\xi\left(v_{r}\right)\right)\left(\mathbf{B}_{(r)}^{l}\right)^{-1}+\xi\left(v_{r}\right)\left(\mathbf{B}_{(r)}^{u}\right)^{-1}\right]^{-1} \text { and } \\
& \mathbf{B}_{(r)}^{l}=\left[\mathbf{I}+\mathcal{E}_{(m)}:\left(\mathbf{D}_{(m)}^{-1}: \mathbf{D}_{(r)}-\mathbf{I}\right)\right]^{-1}, \\
& \mathbf{B}_{(r)}^{u}=\mathbf{I}+\mathcal{E}_{(r)}:\left(\mathbf{D}_{(r)}^{-1}: \mathbf{D}_{(m)}-\mathbf{I}\right) .
\end{aligned}
$$

In Eq. 7, $\xi\left(v_{r}\right)$ is a smooth interpolation function, and $\mathbf{B}_{(r)}^{l}, \mathbf{B}_{(r)}^{u}$ are the regular and inverse MT strain concentration tensors, respectively. Furthermore, $\mathbf{D}_{(r)}$ and $\mathbf{D}_{(m)}$ are reference tangent moduli of inclusion phase $r$ and the matrix phase, as computed with the average strain rates of that phase, and $\mathcal{E}_{(m)}, \mathcal{E}_{(r)}$ denote the Eshelby tensor computed using the matrix or the inclusion reference moduli, respectively. The present homogenization scheme and its implementation is largely based on the work presented in [38], from which additional details can be found. They studied composites consisting of an elasto-plastic matrix phase reinforced with elastic inclusions, and found that using the tangent moduli when computing the Eshelby tensor gave overly stiff predictions in terms of overall response. To solve this issue it was suggested to use an isotropic projection of the tangent moduli, $\mathbf{D}^{i s o}$, to calculate $\mathcal{E}$. In connection to this, it is stated that for the per-phase behaviour, however, depending on the relative properties of the inclusion and the matrix, and on the loading conditions, using $\mathbf{D}^{i s o}$ to calculate the Eshelby tensor $\mathcal{E}$ leads, in some cases, to an underestimation of the magnitude of stress in the inclusion compared to finite element calculations [13]. Then in turn, an underestimation of the local average fields might contribute to an over-prediction of the overall ductility. When both matrix and inclusion phases are elasto-plastic, however, the homogenization scheme predicts reasonable overall properties as compared to experiments (see Section 4.1). Therefore, we proceed by evaluating the Eshelby tensor using 
D numerically using the method proposed by Lagoudas and Gavazzi [40].

\subsection{Properties of constituents}

The input data for the homogenization of composites with varying microstructure are material grades assumed as single phase microstructures. How the single phase grades are produced is described in section 2. Each constituent phase is assumed to obey $J_{2}$ elasto-plasticity with isotropic hardening according to a power law flow stress model

$$
\sigma_{Y(r)}=f_{r}^{c} \sigma_{Y 0(r)}+K_{r}\left(\bar{\varepsilon}_{r}^{p}\right)^{m_{r}}
$$

where $f_{r}^{c}$ is a scaling factor taking microstructural effects in composites into account; $\sigma_{Y 0(r)}, K_{r}, m_{r}$ and $\bar{\varepsilon}_{r}^{p}$ are the initial yield stress, strength coefficient and hardening exponent of phase $r$. It is further assumed that differences in isotropic elastic properties of the constituents are negligible, rendering in a homogeneous elastic response.

During diffusive decomposition of austenite into daughter phases, carbon migrates from the newly formed phase into the remaining austenite. This is true for the formation of ferrite, it is less true for lower bainite but even for that phase much of the carbon is partitioned into the austenite rather than precipitating as carbides. If this process is followed by a quenching transformation the martensite will contain a larger amount of carbon than the bulk content, thus increasing the martensite yield strength. The carbon content of the remaining austenite, $C_{\gamma}$, can be estimated from mass balance considerations,

$$
C_{\gamma}=\frac{\bar{C}-\sum_{r} v_{r} C_{(r)}}{1-\sum_{r} v_{r}}
$$

where $\bar{C}$ is the bulk carbon content, $v_{r}$ the volume fraction of formed phase $r$ and $C_{(r)}$ is the carbon phase $r$ can hold. The initial yield stress and the carbon content of carbon steels show a correlation and should be taken into account [41]. Calculating the carbon content in the remaining austenite the scaling factor of the initial yield stress for martensite, $f_{m}^{c}$, is

$$
f_{m}^{c}=\left(\frac{\bar{C}}{C_{\gamma}}\right)^{\frac{1}{2}}
$$

A strengthening effect in microstructures consisting of lower bainite and martensite is found [42]. A quantitative relationship between the volume fraction of bainite $v_{b}$ and the strength of the mixed microstructure is proposed [43].

$$
f_{b}^{c}=0.65 e^{-3.3 v_{b}}+0.98
$$

The strengthening effect in this type of mixed microstructure is explained by two major contributions. The first is the increase in the strength of martensite as carbon is partitioned into austenite during the formation of bainite, the second effect is a plastic constraint in which the strength of bainite is enhanced. Eq. 11 is calibrated to a steel with different alloying, no recalibration was performed for this study. 


\subsection{Ductile fracture}

The progressive nucleation, growth and coalescence of micro voids during plastic loading ultimately lead to macroscopic crack initiation in ductile metals. This mechanism is influenced by the microscopic field quantities and the nucleation or growth resistance of each constituent phase and interfaces present. We consider the nucleation process being the dominant factor, and assume that this process is mainly controlled by the local average stress field acting in the microscopic scale. Furthermore, a distinction is made between two cases. 1: intra-phase fracture; void nucleation caused by microcracking within grains or interface decohesion between adjacent grains of the same phase, and 2: interphase fracture; void nucleation caused by interface decohesion between adjacent grains of different phases. A line of thought supported by $[44,45,46]$ who identified decohesion of the ferrite-martensite interface as one mechanism of void nucleation and that those voids grow along ferrite grain boundaries.

It is assumed, for case 1, that the intra-phase strength is governed by a ductile fracture criterion on the form suggested by Khan and Liu [25], abbreviated the MSV criterion. The MSV criterion involves the magnitude of the stress vector, $M S V$,

$$
M S V=\left(\sigma_{1}^{2}+\sigma_{2}^{2}+\sigma_{3}^{2}\right)^{1 / 2}=\left(3\left(\bar{\sigma}^{\text {mean }}\right)^{2}+\frac{2}{3} \bar{\sigma}^{2}\right)^{1 / 2}
$$

as the fracture indicator, where $\sigma_{i}, i=1,2,3$ are the principal stresses, and the criterion is given by

$$
M S V=c_{1}\left(\bar{\sigma}^{\text {mean }}\right)^{2}+c_{2} \bar{\sigma}^{\text {mean }}+c_{3},
$$

where $\bar{\sigma}^{\text {mean }}$ is the hydrostatic mean stress and $c_{1}-c_{3}$ are model parameters. For loading conditions involving dependence on tension and compression two different quadratic expressions for the positive and negative hydrostatic mean stress regions are necessary [25]. We consider only the positive region as being of relevance for thin-walled structures. This criterion is established in terms of the microscopical average stress acting within each phase, so that Eqs. $(12,13)$ read

$$
\begin{aligned}
\langle M S V\rangle_{(r)} & =\left(3\left\langle\bar{\sigma}^{\text {mean }}\right\rangle_{(r)}^{2}+\frac{2}{3}\langle\bar{\sigma}\rangle_{(r)}^{2}\right)^{1 / 2} \\
\langle M S V\rangle_{(r)} & =c_{1(r)}\left\langle\bar{\sigma}^{\text {mean }}\right\rangle_{(r)}^{2}+c_{2(r)}\left\langle\bar{\sigma}^{\text {mean }}\right\rangle_{(r)}+c_{3(r)},
\end{aligned}
$$

where $\langle\bar{\sigma}\rangle_{(r)},\left\langle\bar{\sigma}^{\text {mean }}\right\rangle_{(r)}$ are the local average effective stress and mean hydrostatic stress, respectively, acting within phase $r$.

For case 2, the inter-phase strength is governed by a critical maximum principal stress criterion, given by

$$
\max \left(\left\langle\sigma_{1}\right\rangle_{(r)}\right)=\min \left(\sigma_{r}^{c r i t}\right),
$$

for all phases $r$ present. This means that if the maximum major principal stress of all phases present, $\max \left(\left\langle\sigma_{1}\right\rangle_{(r)}\right)$, equals the strength of the weakest interface present, $\min \left(\sigma_{r}^{\text {crit }}\right)$, fracture occurs. 
These two criteria are integrated with the mean field homogenization scheme. Whichever criterion is violated first, either the intra-phase criterion in any of the present phases, or the inter-phase criterion, determines the fracture initiation limit of the multiphase material. With this formulation, the weakest link of the composite material governs the effective ductility.

\subsubsection{Microstructural effects on constituent fracture properties}

A natural assumption would be that the fracture stress of martensite and bainite increases with carbon content, as is the case for the flow stress. However, the relationship between fracture limit stress and carbon content could not be fully investigated in this work, since only one steel composition, $22 \mathrm{MnB} 5$, was used. Therefore, we assume values applicable to the martensite tested. The fracture criteria of the preceding section are evaluated with the reduced local average stress tensor components according to

$$
\begin{gathered}
\left\langle\sigma_{i j}\right\rangle_{(r)}=\left\langle\sigma_{i j}^{\text {dev }}\right\rangle_{(r)} f_{r}^{s c}+\left\langle\bar{\sigma}^{\text {mean }}\right\rangle_{(r)} \delta_{i j}, \text { where } \\
f_{r}^{s c}=\frac{\sigma_{Y 0(r)}+K_{r}\left(\bar{\varepsilon}_{r}^{p}\right)^{m_{r}}}{f_{r}^{c} \sigma_{Y 0(r)}+K_{r}\left(\bar{\varepsilon}_{r}^{p}\right)^{m_{r}}} .
\end{gathered}
$$

Which is essentially the stress tensor without carbon dependent yield stress scaling. Observe that only the fracture criteria are evaluated using the reduced stress tensor.

\subsection{Parameter estimation}

For the preceding micromechanical simulations, constitutive data including fracture parameters for each constituent phase, i.e. ferrite, bainite and martensite, are needed. These parameters were obtained from plasticity and fracture experiments as described in Sec. 2.4, using the specimens consisting of predominantly one constituent phase, see Sec. 2.2.2. Piecewise linear flow curves were determined from the full-field measurements, using specimen geometries \#1, \#2

and \#5. Then the flow stress model, Eq. 8, was fitted by least squares to the piecewise linear measured flow curves of those three specimen geometries per constituent phase. The result is shown in Fig. 5a. The parameters for ferrite and bainite were obtained in an earlier study, see [47], parameters for martensite were determined within the framework of the present study. The parameters are given in Table 2, followed by short discussion of the parameter estimation of each constituent phase.

\section{Results}

\subsection{Overall flow behaviour}

The experimentally obtained flow curves for all multiphase materials, with phase volume fractions given in Table 1 and determined using specimen geometry \#1, are shown in Figs. 6a - 6d. These are flow curves that extend beyond the onset of necking, up to large strains. Also included in Figs. 6a - 6d are 
Table 2: Material parameters.

\begin{tabular}{lcccccccc}
\hline Phase & \multicolumn{9}{c}{ Plow stress model } & \multicolumn{3}{c}{ Parameter } \\
& $f^{c}$ & $\sigma_{Y 0}$ & $K$ & $m$ & $c_{1}$ & $c_{2}$ & $c_{3}$ & $\sigma^{\text {crit }}$ \\
& $(-)$ & $(\mathrm{MPa})$ & $(\mathrm{MPa})$ & $(-)$ & $(\mathrm{MPa})$ & $(-)$ & $(\mathrm{MPa})$ & $(\mathrm{MPa})$ \\
\hline Ferrite & 1 & 203 & 724 & 0.1820 & $1.284 \mathrm{e}-3$ & 0.1093 & 755.0 & 1650 \\
Bainite & Eq.11 & 306 & 916 & 0.0942 & $6.564 \mathrm{e}-4$ & 0.2997 & 996.4 & $\infty$ \\
Martensite & Eq.10 & 400 & 1517 & 0.0661 & $6.005 \mathrm{e}-4$ & 0.1287 & 1545.0 & $\infty$ \\
\hline
\end{tabular}

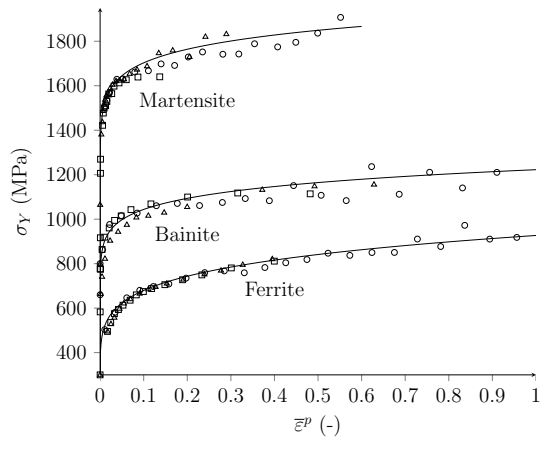

(a) Flow curves.

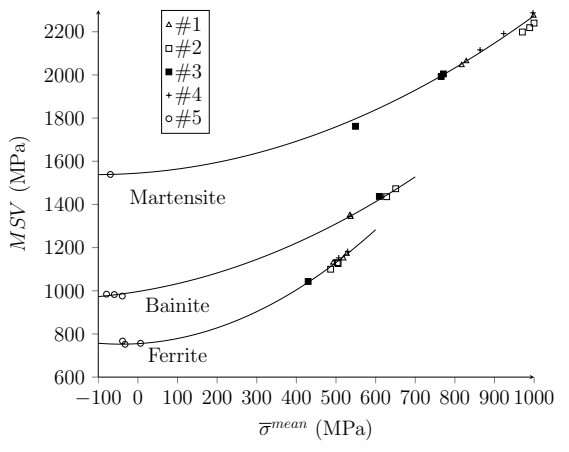

(b) Fracture limit curves.

Figure 5: Flow and fracture limit curves for each constituent phase. In (a), the power-law fit and the corresponding points obtained from Eq. 1 are shown. The fracture criterion is illustrated in (b), where squares, triangles etc. indicate fracture initiation as obtained from experiments, and the solid lines are the fracture limit curves according to the MSV criterion. The legend entries in (b) refer to the test specimen number as depicted in Fig. 1, and applies to (a) and (b).

the overall flow behaviour of all material compositions as predicted by the DI model. As expected, most satisfactory agreement in terms of measurements and predictions are obtained for ferrite-bainite dual phase steels, since these have the least contrast in mechanical properties of the constituents. Generally, the initial amount of hardening at small plastic strains is overpredicted to various degrees. All in all, the agreement with respect to experiments are reasonably good, except for the BM-1 specimen. It seems that the strengthening effect at low bainite fractions of bainite-martensite compositions could not be captured with Eq. 11, suggesting that this relation should be recalibrated for the present alloy.

\subsection{Overall ductility}

The influence of different microstructure compositions on the overall ductility of the boron alloyed steel is shown in Figs. 7a - 7c, as obtained from specimen geometry \#1 . The ductile fracture criteria formulated in the local average stress space are path independent, however, the stress distribution within a RVE depends on the reference moduli which are history dependent, thus introducing a slight path dependence on the overall ductility predictions 

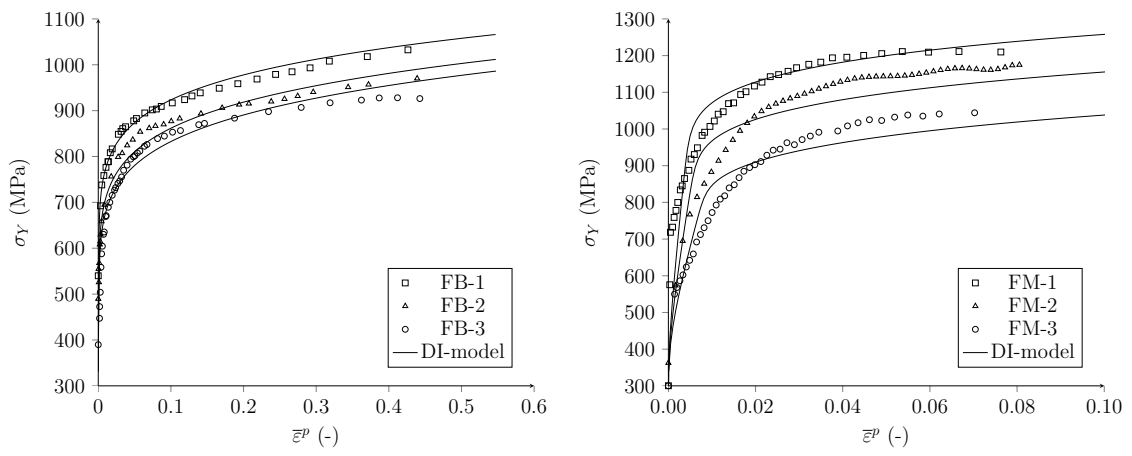

(a) Flow curves of ferrite-bainite

(b) Flow curves of ferrite-martensite
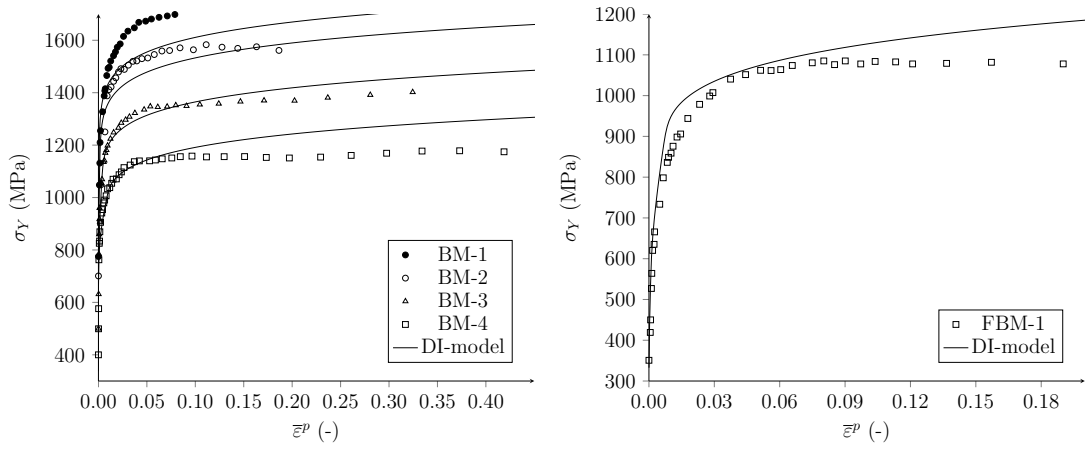

(c) Flow curves of bainite-martensite

(d) Flow curve of ferrite-bainite-

martensite

Figure 6: Experimentally obtained and predicted flow curves for the multiphase steels with different microstructure compositions

by the double-inclusion model. Furthermore, the objective is to study the influence of microstructure separately from the effect of loading condition on ductile fracture. Consequently, in the following comparisons, the DI model was integrated along the average of the experimentally measured strain path of the point where fracture initiates, for each group of tests. Thus, these results are specific to specimen geometry \#1. For those cases where the model overpredicts the overall ductility, the load path was extrapolated linearly, but with a cutoff value at $\beta=0.0$, where $\beta$ is the in-plane principal strain rate ratio. This cutoff value corresponds to a loading state of generalized plastic plane strain. The measured and calculated overall ductility are illustrated in Figs. 7a - 7c, in the space of macroscopic equivalent fracture initiation strain, $\bar{\varepsilon}^{f}$, and relative volume content of constituent phases, and the values are presented in Table (3). Some general trends can be observed from these results. It seems, for all dual phase microstructures in this investigation, that the overall ductility limit diminishes for volume fractions of stronger phase exceeding around $30 \%$ compared to the ductility of the stronger phase alone. Concerning the ferritebainite dual phase steels, the model indicates intra-phase fracture occurring in 


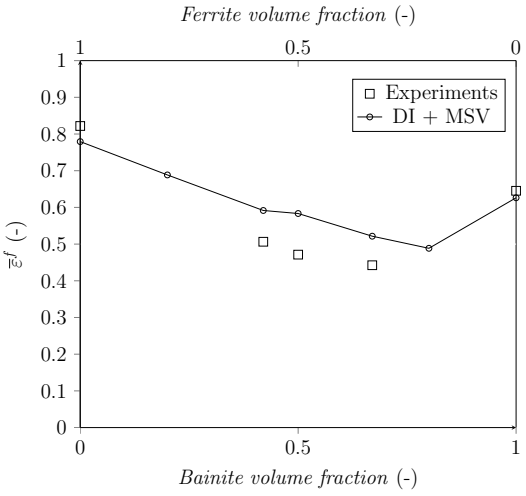

(a) Ferrite matrix with bainitic inclusions.

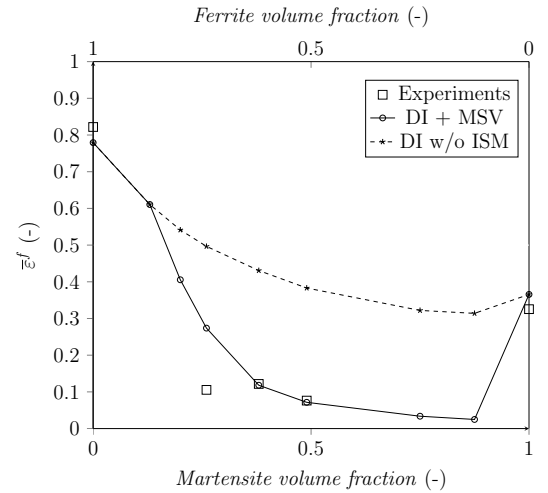

(b) Ferrite matrix with martensitic inclusions.

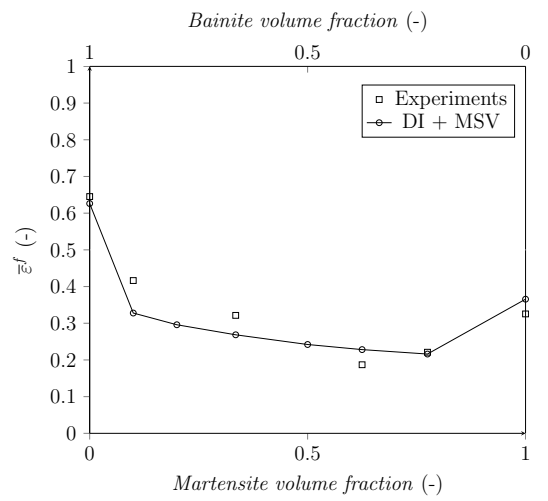

(c) Bainite matrix with martensitic inclusions.

Figure 7: Overall ductility of dual phase microstructures, measurement and prediction.

the bainitic inclusions, for all volume fractions reported. The overall ductility of these grades is systematically overpredicted with an average relative error fraction of approximately 0.2 .

The ferrite-martensite dual phase steels show a remarkable loss of ductility compared to that of the constituent phases alone. This behavior was observed for several additional samples with ferritic-martensitic microstructure of boron alloyed steel not included in this investigation. Commercial steels of this type normally show higher ductility. They differ in chemical composition and, for the most part, go through a post-quench tempering process to reduce some of the internal stresses due to phase transformation as well as to reduce the hardness of the martensite. Ferrite-martensite samples in this study contain relatively large volume fractions of martensite and did not undergo further heat treatment after quenching.

The low ductility limit of the ferrite-martensite steels was the prime motiva- 
Table 3: Fracture strain of specimen \#1.

\begin{tabular}{lccr}
\hline Specimen & Experiment & Prediction & Relative error \\
\hline F730 & 0.8219 & 0.7793 & 0.0518 \\
B1015 & 0.6453 & 0.6262 & 0.0295 \\
M1660 & 0.3254 & 0.3656 & -0.1234 \\
\hline FB-1 & 0.5064 & 0.5916 & -0.1683 \\
FB-2 & 0.4713 & 0.5834 & -0.2378 \\
FB-3 & 0.4424 & 0.5215 & -0.1788 \\
\hline FM-1 & 0.1055 & 0.2738 & -1.5956 \\
FM-2 & 0.1216 & 0.1181 & 0.0288 \\
FM-3 & 0.0763 & 0.0716 & 0.0614 \\
\hline BM-1 & 0.4164 & 0.3278 & 0.2127 \\
BM-2 & 0.3215 & 0.2685 & 0.1647 \\
BM-3 & 0.1870 & 0.2282 & -0.2205 \\
BM-4 & 0.2210 & 0.2161 & 0.0222 \\
\hline FBM-1 & 0.1864 & 0.1696 & 0.0900 \\
\hline
\end{tabular}

tion to include the interface strength model in the present modeling approach. For martensite volume fractions exceeding about 20\%, the interface strength model governs the predicted overall ductility, which is rapidly reduced with increasing martensite content. The predicted rate of decrease is smaller than what is indicated by the experimental results, resulting in a large overprediction of the fracture initiation strain of the FM-1 grade. For the other two, the agreement is surprisingly good. According to the model, vanishingly small fractions of ferrite embedded within a martensitic structure results in a drastic reduction of ductility. Additional experimental data is needed to reject or support this behavior. Also included in Fig. $7 \mathrm{~b}$ are model predictions with the interface strength model deactivated, to illustrate the expected ductility limit in the case of infinite ferrite interface strength.

The third dual phase steel type investigated in this work is the bainitemartensite microstructure. The model indicates intra-phase fracture occurring in the bainitic phase, for all volume fractions reported. For martensite fractions lower than approximately 50\%, the predicted values are conservative.

For the triple-phase steel, the model predicts the fracture initiation strain quite accurately, shown in Table 3, and indicates ferrite interface fracture. A behavior supported by Zare and Ekrami [48] who investigated triple-phase ferritebainite-martensite steels and identified interface decohesion as a primary mechanism due to the density of dislocations at interphase boundaries.

To summarize the preceding discussion, it seems that the integrated MFH scheme and weakest link fracture criterion can to a certain degree explain and provide additional insight the observed fracture behavior of boron alloyed steel. 


\subsection{Uncertainties}

A major practical difficulty in the use of multi-scale methods is the identification of material properties of the individual constituents. A principal assumption of this work is that the single phase specimens can be considered homogeneous, and that the measured properties obtained from macroscopic tensile tests of those specimens can describe the in-situ response of the constituents at the microscale. This is off course not strictly valid, since these specimens are heterogeneous to various degrees. How accurately the mechanical properties of the irregular ferrite in specimen F730 corresponds to the properties of the proeutectoid ferrite phase present in the multiphase microstructures is difficult to estimate. The same applies to bainite, a phase which can show quite different mechanical properties depending on transformation temperature. Moreover, the simplifications inherent to the MFH scheme relative to the physics of the problem, such as phase-wise constant fields, topological simplifications, strict validity only to small strains etc., in combination with local fracture criteria, are certainly debatable. The present approach shows a viable way forward for the microstructure-based modeling of ductile fracture initiation in press-hardened steels, but more research is needed in order to quantify these aforementioned uncertainties.

The phase volume fractions were determined from image analysis of SEM micrographs taken from a small region of the tensile specimens. Within this small region, the variation of volume fractions was estimated to be about $\pm 2-$ $4 \%$. However, two independent characterizations, both using essentially the same methods as earlier described, have indicated a higher uncertainty. The processing conditions should ensure an even temperature distribution within the gauge length of the specimen, an assertion supported by hardness measurements across the gauge length which showed no significant variations.

\section{Conclusion}

An experimental investigation of the ductile fracture properties of boron steel with eleven mixed microstructures consisting of different phase compositions, and volume fractions thereof, was conducted. Tensile test specimens underwent thermal treatment followed by characterization of mechanical properties using full-field measurements and microstructure characterization using SEM imaging. This enabled mapping of the influence of constituent phase volume fractions on the overall flow and ductile fracture properties. Results revealed significant ductility variations depending on microstructure, which motivated the formulation of two independent local fracture criteria in the framework of a mean-field homogenization scheme. The flow and fracture properties of each constituent was identified experimentally from tensile specimens with what was considered as single phase microstructures. Certain additional microstructural effects such as the influence of carbon content on the constituents yield strength were taken into account. The proposed modeling approach which separates inter-phase and intra-phase fracture mechanisms could reproduce the experimental observations 
with useful accuracy. This confirms to some extent that the different fracture modes observed can be explained by the model, for the material compositions studied in this work. This also indicates that a mean-field homogenization approach combined with local fracture criteria can be an efficient approach to the constitutive and ductile fracture modeling for estimating the performance envelopes of components with distributed microstructure composition.

\section{Acknowledgments}

Economic support for this work is supplied by VINNOVA through the project FFI OPTUS2 nr 2009-04597 which is gratefully acknowledged. The authors wish to acknowledge the supply of blanks by Gestamp HardTech Luleå. Mr Hans Åhlin is gratefully acknowledged for development of the plane hardening tool. Also the support with experiment execution by Mr Jan Granström is acknowledged.

\section{References}

[1] Ảkerström P, Oldenburg M. Austenite decomposition during press hardening of a boron steel: computer simulation and test. Journal of Materials Processing Technology 2006;174(1-3):399-406. doi:http://dx.doi.org/10.1016/j.jmatprotec.2006.02.013.

[2] Ȧkerström P, Bergman G, Oldenburg M. Numerical implementation of a constitutive model for simulation of hot stamping. Modelling and Simulation in Materials Science and Engineering 2007;15(2):105. doi:http://dx.doi.org/10.1088/0965-0393/15/2/007.

[3] Min J, Lin J, Min Y, Li F. On the ferrite and bainite transformation in isothermally deformed 22mnb5 steels. Materials Science and Engineering: A 2012;550:375 -87. doi:http://dx.doi.org/10.1016/j.msea.2012.04.091.

[4] Chang Y, Li X, Zhao K, Wang C, Zheng G, Hu P, et al. Influence of stress on martensitic transformation and mechanical properties of hot stamped \{AHSS $\}$ parts. Materials Science and Engineering: A 2015;629:1 - 7. doi:http://dx.doi.org/10.1016/j.msea.2015.01.056.

[5] Nikravesh M, Naderi M, Akbari G. Influence of hot plastic deformation and cooling rate on martensite and bainite start temperatures in 22mnb5 steel. Materials Science and Engineering: A 2012;540:24 -9. doi:http://dx.doi.org/10.1016/j.msea.2012.01.018.

[6] Bardelcik A, Worswick MJ, Winkler S, Wells MA. A strain rate sensitive constitutive model for quenched boron steel with tailored properties. International Journal of Impact Engineering 2012;50(0):49 - 62. doi:http://dx.doi.org/10.1016/j.ijimpeng.2012.06.007. 
[7] Bardelcik A, Worswick MJ, Wells MA. The influence of martensite, bainite and ferrite on the as-quenched constitutive response of simultaneously quenched and deformed boron steel - experiments and model. Materials \& Design 2014;55(0):509 -25. doi:http://dx.doi.org/10.1016/j.matdes.2013.10.014.

[8] Eller TK, Greve L, Andres MT, Medricky M, Hatscher A, Meinders VT, et al. Plasticity and fracture modeling of quench-hardenable boron steel with tailored properties. Journal of Materials Processing Technology 2014;214(6):1211 -27 . doi:http://dx.doi.org/10.1016/j.jmatprotec.2013.12.015.

[9] Östlund R, Berglund D, Oldenburg M. Failure model evaluation for varying microstructure base on material hardness. In: Oldenburg M, Prakash B, Steinhoff K, editors. Hot sheet metal forming of high performance steel. Verlag Wissenschaftliche Scripten; 2011, p. 41-8.

[10] Zaoui A. Continuum micromechanics: Survey. Journal of Engineering Mechanics 2002;128(8):808-16. doi:10.1061/(ASCE)07339399(2002)128:8(808).

[11] Mercier S, Molinari A, Berbenni S, Berveiller M. Comparison of different homogenization approaches for elasticviscoplastic materials. Modelling and Simulation in Materials Science and Engineering 2012;20(2):024004.

[12] Golling S, Östlund R, Oldenburg M. A study on homogenization methods for steels with varying content of ferrite, bainite and martensite. Journal of Materials Processing Technology 2016;228:88-97. doi:http://dx.doi.org/10.1016/j.jmatprotec.2015.07.007.

[13] Tekoglu C, Pardoen T. A micromechanics based damage model for composite materials. International Journal of Plasticity 2010;26(4):549 -69. doi:http://dx.doi.org/10.1016/j.ijplas.2009.09.002.

[14] Pierman AP, Bouaziz O, Pardoen T, Jacques PJ, Brassart L. The influence of microstructure and composition on the plastic behaviour of dual-phase steels. Acta Materialia 2014;73(0):298 - 311. doi:http://dx.doi.org/10.1016/j.actamat.2014.04.015.

[15] Bai Y, Wierzbicki T. A comparative study of three groups of ductile fracture loci in the 3d space. Engineering Fracture Mechanics 2015;135(0):147 -67. doi:http://dx.doi.org/10.1016/j.engfracmech.2014.12.023.

[16] Li Y, Wierzbicki T. Prediction of plane strain fracture of AAHSS $\}$ sheets with post-initiation softening. International Journal of Solids and Structures 2010;47(17):2316 -27. doi:http://dx.doi.org/10.1016/j.ijsolstr.2010.04.028. 
[17] Brünig M, Brenner D, Gerke S. Stress state dependence of ductile damage and fracture behavior: Experiments and numerical simulations. Engineering Fracture Mechanics 2015;141(0):152 -69. doi:http://dx.doi.org/10.1016/j.engfracmech.2015.05.022.

[18] Brünig M, Gerke S, Hagenbrock V. Stress-state-dependence of damage strain rate tensors caused by growth and coalescence of microdefects. International Journal of Plasticity 2014;63(0):49 - 63 . doi:http://dx.doi.org/10.1016/j.ijplas.2014.04.007; deformation Tensors in Material Modeling in Honor of Prof. Otto T. Bruhns.

[19] Li H, Fu MW, Lu J, Yang H. Ductile fracture: Experiments and computations. International Journal of Plasticity 2011;27(2):147 -80. doi:http://dx.doi.org/10.1016/j.ijplas.2010.04.001.

[20] Malcher L, Andrade Pires FM, César de Sá JMA. An assessment of isotropic constitutive models for ductile fracture under high and low stress triaxiality. International Journal of Plasticity 2012;3031(0):81 - 115. doi:http://dx.doi.org/10.1016/j.ijplas.2011.10.005.

[21] Bai Y, Wierzbicki T. A new model of metal plasticity and fracture with pressure and lode dependence. International Journal of Plasticity 2008;24(6):1071 -96. doi:http://dx.doi.org/10.1016/j.ijplas.2007.09.004.

[22] Johnson GR, Cook WH. Fracture characteristics of three metals subjected to various strains, strain rates, temperatures and pressures. Engineering Fracture Mechanics 1985;21(1):31 - 48. doi:http://dx.doi.org/10.1016/0013-7944(85)90052-9.

[23] Hooputra H, Gese H, Dell H, Werner H. A comprehensive failure model for crashworthiness simulation of aluminium extrusions. International Journal of Crashworthiness 2004;9(5):449-64. doi:10.1533/ijcr.2004.0289.

[24] Cockcroft MG, Latham DJ. Ductility and the workability of metals. Journal Institute of Metals 1968;96:33-9.

[25] Khan AS, Liu H. A new approach for ductile fracture prediction on al 2024-t351 alloy. International Journal of Plasticity 2012;35(0):1 - 12. doi:http://dx.doi.org/10.1016/j.ijplas.2012.01.003.

[26] Oldenburg M, Lindkvist G. Tool thermal conditions for tailored material properties. Journal of Heat Treatment and Materials 2011;66(6):329-34.

[27] George R, Bardelcik A, Worswick MJ. Hot forming of boron steels using heated and cooled tooling for tailored properties. Journal of Materials Processing Technology 2012;212:2386-99. doi:http://dx.doi.org/10.1016/j.jmatprotec.2012.06.028. 
[28] Meza-Garcia E, Mosel A, Shchus Y, Rautenstrauch A, Lachmann L, Schieck F, et al. Design of heat treatment processes for a tailored set of properties on $22 \mathrm{mnb} 5$ steel alloy sheets simulation and experiments. In: Oldenburg M, Steinhoff K, Prakash B, editors. Hot sheet metal forming of high-performance steel, CHS2: 4th international conference. Verlag Wissenschaftliche Scripten; 2013, p. 337-44.

[29] Wang K, Luo M, Wierzbicki T. Experiments and modeling of edge fracture for an ahss sheet. International Journal of Fracture 2014;187(2):245-68. doi:http://dx.doi.org/10.1007/s10704-014-9937-5.

[30] Berglund D. Hot stamped components with tailored properties - simulation and validation of product performance. In: Oldenburg M, Steinhoff K, Prakash B, editors. Hot sheet metal forming of high-performance steel, CHS2: 2nd international conference. Verlag Wissenschaftliche Scripten; 2009, p. $229-36$.

[31] Gruben G, Vysochinskiy D, Coudert T, Reyes A, Lademo OG. Determination of ductile fracture parameters of a dual-phase steel by optical measurements. Strain 2013;49(3):221-32.

[32] Park K, Nishiyama M, Nakada N, Tsuchiyama T, Takaki S. Effect of the martensite distribution on the strain hardening and ductile fracture behaviors in dual-phase steel. Materials Science and Engineering: A 2014;604:135 -41. doi:http://dx.doi.org/10.1016/j.msea.2014.02.058.

[33] Eman J. Study and characterization of localization and failure behaviour of ultra high strength steel. Licenciate thesis; 2007. Lulea University of Technology.

[34] Östlund R, Oldenburg M, Häggblad HÅ, Berglund D. Evaluation of localization and failure of boron alloyed steels with different microstructure compositions. Journal of Materials Processing Technology 2014;214(3):592 -8. doi:http://dx.doi.org/10.1016/j.jmatprotec.2013.09.022.

[35] Eshelby JD. The determination of the elastic field of an ellipsoidal inclusion, and related problems. Proceedings of the Royal Society of London Series A Mathematical and Physical Sciences 1957;241(1226):376-96. doi:10.1098/rspa.1957.0133.

[36] Mori T, Tanaka K. Average stress in matrix and average elastic energy of materials with misfitting inclusions. Acta Metallurgica 1973;21(5):571 -4. doi:http://dx.doi.org/10.1016/0001-6160(73)90064-3.

[37] Lielens G, Pirotte P, Couniot A, Dupret F, Keunings R. Prediction of thermo-mechanical properties for compression moulded composites. Composites Part A: Applied Science and Manufacturing 1998;29(12):63 70. doi:http://dx.doi.org/10.1016/S1359-835X(97)00039-0; selected Papers Presented at the Fourth International Conference on Flow Processes in Composite Material. 
[38] Doghri I, Ouaar A. Homogenization of two-phase elasto-plastic composite materials and structures: Study of tangent operators, cyclic plasticity and numerical algorithms. International Journal of Solids and Structures 2003;40(7):1681 -712. doi:http://dx.doi.org/10.1016/S00207683(03)00013-1.

[39] Hori M, Nemat-Nasser S. Double-inclusion model and overall moduli of multi-phase composites. Mechanics of Materials 1993;14(3):189 - 206. doi:http://dx.doi.org/10.1016/0167-6636(93)90066-Z.

[40] Gavazzi AC, Lagoudas DC. On the numerical evaluation of eshelby's tensor and its application to elastoplastic fibrous composites. Computational Mechanics 1990;7(1):13-9. doi:http://dx.doi.org/10.1007/BF00370053.

[41] Speich GR, Warlimont H. Yield strength and transformation substructure of low-carbon martensite. J Iron Steel Inst 1968;206(4).

[42] Tomita Y, Okabayashi K. Improvement in lower temperature mechanical properties of 0.40 pct c-ni-cr-mo ultrahigh strength steel with the second phase lower bainite. Metallurgical Transactions A 1983;14(2):485-92. doi:http://dx.doi.org/10.1007/BF02644225.

[43] Young CH, Bhadeshia HKDH. Strength of mixtures of bainite and martensite. Materials Science and Technology 1994;10(3):209-14. doi:http://dx.doi.org/10.1179/mst.1994.10.3.209.

[44] Avramovic-Cingara G, Ososkov Y, Jain MK, Wilkinson DS. Effect of martensite distribution on damage behaviour in dp600 dual phase steels. Materials Science and Engineering: A 2009;516(12):7 - 16. doi:http://dx.doi.org/10.1016/j.msea.2009.03.055.

[45] Saai A, Hopperstad O, Granbom Y, Lademo OG. Influence of volume fraction and distribution of martensite phase on the strain localization in dual phase steels. Procedia Materials Science 2014;3:900 -5. 20th European Conference on Fracture.

[46] Alharbi K, Ghadbeigi H, Efthymiadis P, Zanganeh M, Celotto S, Dashwood $\mathrm{R}$, et al. Damage in dual phase steel dp1000 investigated using digital image correlation and microstructure simulation. Modelling and Simulation in Materials Science and Engineering 2015;23(8):085005.

[47] Östlund R, Oldenburg M, Häggblad HÅ, Berglund D. Numerical failure analysis of steel sheets using a localization enhanced element and a stress based fracture criterion. International Journal of Solids and Structures 2015;56-57(0):1 - 10. doi:http://dx.doi.org/10.1016/j.ijsolstr.2014.12.010.

[48] Zare A, Ekrami A. Influence of martensite volume fraction on tensile properties of triple phase ferritebainitemartensite steels. Materials Science and Engineering: A 2011;530(0):440 -5. doi:http://dx.doi.org/10.1016/j.msea.2011.09.108. 